\title{
Constraining the geothermal heat flux in Greenland at regions of radar-detected basal water
}

\section{Paper}

Cite this article: Rezvanbehbahani S, Stearns LA, van der Veen CJ, Oswald GKA, Greve R (2019). Constraining the geothermal heat flux in Greenland at regions of radar-detected basal water. Journal of Glaciology 65(254), 1023-1034. https://doi.org/10.1017/jog.2019.79

Received: 10 April 2019

Revised: 10 October 2019

Accepted: 11 October 2019

First published online: 4 November 2019

Key words:

Basal ice; ice-sheet modeling; melt-basal; radio-echo sounding

\section{Author for correspondence:}

Soroush Rezvanbehbahani,

E-mail: soroushr@ku.edu (c) The Author(s) 2019. This is an Open Access article, distributed under the terms of the Creative Commons Attribution licence (http:// creativecommons.org/licenses/by/4.0/), which permits unrestricted re-use, distribution, and reproduction in any medium, provided the original work is properly cited.

\section{Soroush Rezvanbehbahani ${ }^{1,2}$ (D), Leigh A. Stearns ${ }^{1,2}$, C. J. van der Veen ${ }^{3}$, Gordon K. A. Oswald ${ }^{4}$ (1) and Ralf Greve ${ }^{5}$}

${ }^{1}$ Department of Geology, University of Kansas, Lawrence, KS 66045, USA; ${ }^{2}$ Center for Remote Sensing of Ice Sheets, University of Kansas, Lawrence, KS 66045, USA; ${ }^{3}$ Department of Geography and Atmospheric Science, University of Kansas, Lawrence, KS 66045, USA; ${ }^{4}$ Climate Change Institute, University of Maine, Orono, ME 04469, USA and

${ }^{5}$ Institute of Low Temperature Science, Hokkaido University, Sapporo, Japan

\begin{abstract}
The spatial distribution of basal water critically impacts the evolution of ice sheets. Current estimates of basal water distribution beneath the Greenland Ice Sheet (GrIS) contain large uncertainties due to poorly constrained boundary conditions, primarily from geothermal heat flux (GHF). The existing GHF models often contradict each other and implementing them in numerical ice-sheet models cannot reproduce the measured temperatures at ice core locations. Here we utilize two datasets of radar-detected basal water in Greenland to constrain the GHF at regions with a thawed bed. Using the three-dimensional ice-sheet model SICOPOLIS, we iteratively adjust the GHF to find the minimum GHF required to reach the bed to the pressure melting point, $\mathrm{GHF}_{\mathrm{pmp}}$, at locations of radar-detected basal water. We identify parts of the central-east, south and northwest Greenland with significantly high $\mathrm{GHF}_{\mathrm{pmp}}$. Conversely, we find that the majority of low-elevation regions of west Greenland and parts of northeast have very low $\mathrm{GHF}_{\mathrm{pmp}}$. We compare the estimated constraints with the available GHF models for Greenland and show that GHF models often do not honor the estimated constraints. Our results highlight the need for community effort to reconcile the discrepancies between radar data, GHF models, and ice core information.
\end{abstract}

\section{l. Introduction}

Basal ice temperature plays an important role in controlling ice velocity and consequently, ice-sheet geometry and discharge. If basal ice is at the pressure melting point, basal water is generated which can enhance the sliding velocity. At temperatures lower than the melting point, ice temperature affects ice stiffness and deformational velocity. Therefore, estimating the basal temperature of ice sheets is critical for generating realistic results using numerical ice-sheet models. Our current knowledge about spatial variations of basal temperature, however, is poorly constrained by observations and in situ measurements that only present the local basal temperatures.

The amount of heat generated at the base of an ice sheet governs the basal ice temperature. This heat can derive from three major sources: heat generated from the internal deformation of ice, heat produced from the friction of ice with the glacier bed, and geothermal heat flux from the Earth's interior (GHF). The effect of each of these components on basal conditions varies spatially, primarily based on ice thickness, velocity and tectonic setting. Among these sources, GHF has the largest uncertainty range in the interior regions; apart from a handful of deep ice cores, direct measurements of GHF are not available under the ice sheet.

The importance of spatial variations in GHF on ice-sheet dynamics has been discussed in several studies (e.g. Larour and others, 2012; Rogozhina and others, 2012; Pittard and others, 2016). Modeling studies show that GHF not only affects the basal thermodynamic condition but also alters the thickness and surface geometry of ice sheets (Greve and Hutter, 1995; Larour and others, 2012). Therefore, understanding the spatial distribution of GHF is important for enhancing the robustness of ice-sheet models.

At ice core locations, GHF can be inferred from the measured vertical temperature gradient in the basal ice layer and the thermal conductivity of ice. Measurements from ice cores reveal large variations in GHF over short distances (tens of kilometers) in the Greenland Ice Sheet (GrIS). For example, the estimated GHF from the NGRIP ice core $\left(\sim 140 \mathrm{~mW} \mathrm{~m}^{-2}\right.$, Dahl-Jensen and others, 2003) is more than 50\% higher than GHF measurements at the GRIP ice core, located roughly $300 \mathrm{~km}$ away $\left(51.3 \mathrm{~mW} \mathrm{~m}^{-2}\right.$, Dahl-Jensen and others, 1998). In addition, GHF estimates at the onset of the Northeast Greenland Ice Stream (NEGIS) may be an order of magnitude higher than at the GRIP ice core, only $200 \mathrm{~km}$ away (Fahnestock and others, 2001). In south Greenland, at the location of the Dye-3 ice core, the modeled GHF suggests low values of roughly $20 \mathrm{~mW} \mathrm{~m}^{-2}$ (Gundestrup and Hansen, 1984; Greve, 2005). Among the six deep ice cores shown in Greenland, only two of them contain evidence of basal thaw: NGRIP (Dahl-Jensen and others, 2003) and NEEM (Goossens and others, 2016) (Fig. 1). Although spatial variations in GHF are shown to have significant effects on the thermodynamics of basal ice, they remain a large unknown in Greenland. 

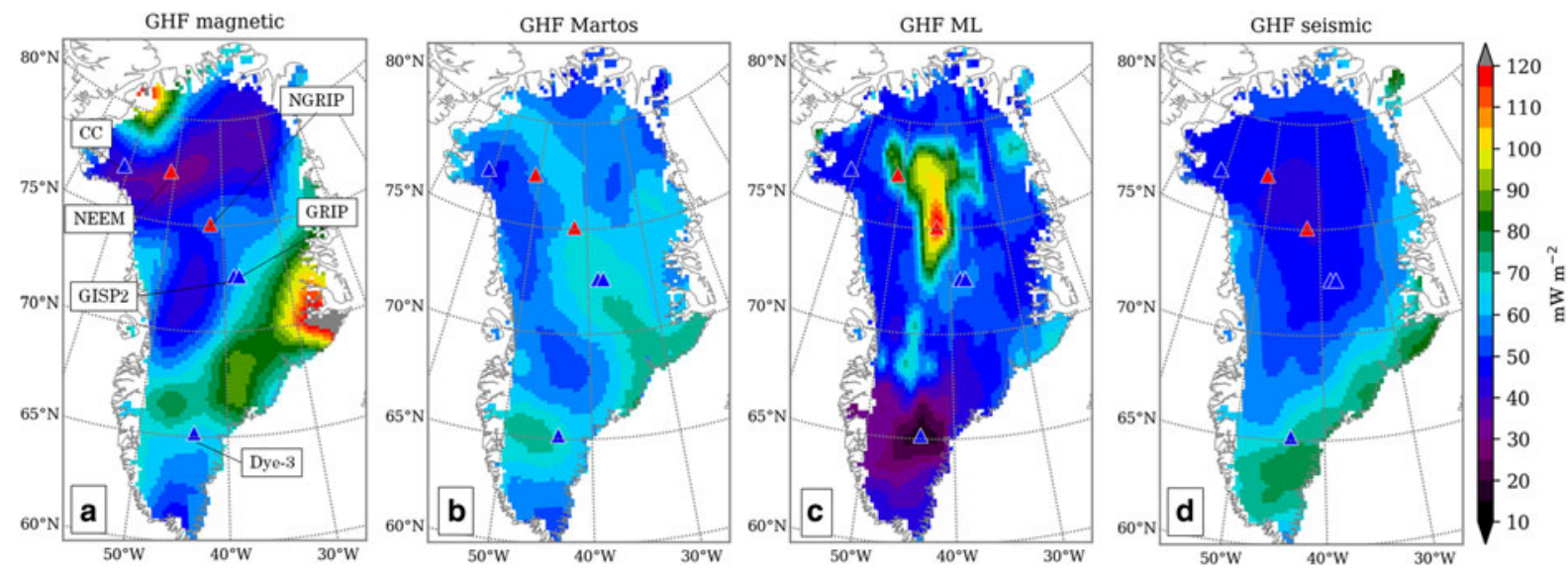

Fig. 1. The GHF maps that are used in this study from (a) Fox Maule and others (2009), (b) Martos and others (2018), (c) Rezvanbehbahani and others (2017)

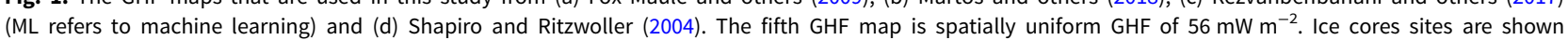
with triangles with blue and red colors indicating observed frozen and thawed basal conditions, respectively. The Camp Century ice core is denoted by CC.

Direct measurements of GHF of the GrIS are limited to a few deep ice core sites. To overcome this limitation, several methods have been developed to predict the spatial patterns of GHF. For example, Fox Maule and others (2009) use remotely-sensed magnetic data to calculate the Curie depth, from which the GHF can be inferred (Fig. 1a). The analysis of magnetic data is advanced by Martos and others (2018) who use spectral analysis to estimate the depth of Curie isotherm in Greenland from high-resolution magnetic anomaly data (Fig. 1b). Rezvanbehbahani and others (2017) train a machine learning algorithm by combining the global GHF measurements and geologic and tectonic properties to predict the GHF in Greenland (Fig. 1c). In addition, seismic tomography models, based on structural similarity functionals, are used to estimate the global GHF (Shapiro and Ritzwoller, 2004) (Fig. 1d), and Greve (2005) and Greve (2019) modify the empirical GHF estimates of Pollack and others (1993) to match the modeled and measured basal temperatures in Greenland ice cores.

Seismic and magnetically-derived maps of Shapiro and Ritzwoller (2004) and Fox Maule and others (2009) have been used in thermo-mechanical ice-sheet models to estimate the basal temperature of the GrIS (e.g. Rogozhina and others, 2012; Seroussi and others, 2013); however, the calculated basal temperatures often do not match deep ice core measurements. Using spatially uniform GHF values in numerical ice-sheet models may yield more accurate results for surface elevation reconstructions and temperature profiles at ice core sites than other GHF models (e.g. Rogozhina and others, 2012). Consequently, applying a spatially uniform GHF for GrIS is still common in modeling studies.

Radar surveys are pivotal in identifying regions with temperate bed or ponded water. Basal water or temperate bed is not explicitly a boundary condition in modeling ice-sheet behavior. However, the existence of basal temperate ice sets an important constraint on the thermal boundary condition of the bed; it implies that the GHF must be larger than a critical value below which the bed would be frozen (referred to as $\mathrm{GHF}_{\mathrm{pmp}}$ ). Therefore, numerical ice-sheet models can implement the spatial distribution of radar-detected basal water to estimate $\mathrm{GHF}_{\mathrm{pmp}}$. Such results are necessary to evaluate the reliability of current GHF models.

This study seeks to improve our understanding of basal thermal conditions of the GrIS by constraining the spatial variations of GHF according to the extent of thawed basal state, predicted by radar data. It also aims at demonstrating and highlighting the contrasts between GHF models and GHF constraints obtained from radar data. We use two datasets that independently predict the location of basal melt of the GrIS. The first dataset is from Oswald and others (2018) where they use the acuity of the reflected radar signals (Oswald and Gogineni, 2008, 2012) to delineate regions where subglacial water likely exists. This dataset identifies thawed regions with substantial basal water thickness $(\sim 3 \mathrm{~cm}$, Oswald and others, 2018). The second dataset is from Jordan and others (2018), who use a 'bed-echo reflectivity variability' method, based on the reflection intensity of the radar signals, to detect wet-dry transitions in the basal material. Both datasets are purely based on radar data and are independent of numerical or GHF models. Note that in both datasets, not detecting temperate ice or ponded water at the bed does not imply that the bed is frozen. In other words, the implemented criteria to determine the basal condition is a necessary condition, but not sufficient.

Here we use the three-dimensional thermo-mechanical icesheet model SICOPOLIS (Greve and Hutter, 1995; Greve, 1997) to iteratively estimate the GHF at locations where basal water is detected. By adjusting the value of GHF at thawed points, we constrain the GHF of the ice sheet so that the basal condition matches the predictions of both of these radar studies. We then compare the $\mathrm{GHF}_{\mathrm{pmp}}$ values with the available GHF maps in Greenland, namely, seismically derived (Shapiro and Ritzwoller, 2004), magnetically derived (Fox Maule and others, 2009), machine learningbased (Rezvanbehbahani and others, 2017, referred to as ML) and the GHF from spectral analysis of high-resolution magnetic data (Martos and others, 2018).

A similar approach has been conducted by Van Liefferinge and Pattyn (2013) and Van Liefferinge and others (2018) in order to identify the possible locations with a frozen bed in East Antarctica in search for the oldest ice. Since the regions that are investigated in those studies are in the interior regions of East Antarctica, vertical one-dimensional models would suffice. However, because some of the regions of interest in our study are near the margins, the effect of horizontal heat advection and thermo-mechanical coupling becomes important (e.g. Rezvanbehbahani and others, $2019 \mathrm{~b})$ and a three-dimensional model is necessary.

The structure of this study is as follows: we first introduce the thermal component of the numerical ice-sheet model, SICOPOLIS and simulation set up (Section 2.1). Then, we explain the two radar datasets of Oswald and others (2018) and Jordan and others (2018) that are used in this study (Section 2.2). We present the results of adjusting the GHF at the locations of radar-detected basal water (Section 3.1), perform sensitivity analysis with respect to different climatic conditions (Section 3.2), and compare the estimated constraints against the GHF models (Section 3.3). We discuss the uncertainty of the estimates, as well as an in-depth comparison with ice core data that reveal several discrepancies between different datasets. Then we investigate several mechanisms 
that can resolve these discrepancies and finally investigate the importance of such constraints on the total melt-water production at the base of the ice sheet (Section 4).

\section{Data and methodology}

\subsection{Ice-sheet model and simulation set-up}

We use the SImulation COde for POLythermal Ice Sheets (SICOPOLIS version 3.3) to iteratively solve for GHF. SICOPOLIS simulates the dynamic and thermodynamic evolution of ice sheets using the Shallow Ice Approximation (SIA, Hutter, 1983). Glacier ice is treated as a heat-conducting incompressible fluid with power-law rheology (Glen, 1955), regularized to avoid infinite viscosities in the limit of small effective stresses (Greve and Blatter, 2009). Given a time-dependent external forcing (climate conditions), SICOPOLIS simulates the temporal evolution of ice thickness, temperature and velocity field.

We model the thermal evolution of GrIS using the enthalpy method (e.g. Aschwanden and others, 2012). This method has the advantage of including temperature and water content in a single thermodynamic variable. Specifically, in order to simulate the thermal evolution of the ice sheet, we use the one-layer melting-CTS enthalpy scheme of SICOPOLIS, which explicitly enforces the transition conditions at the CTS (continuity of the temperature gradient and water content) for any polythermal ice column (Blatter and Greve, 2015; Greve and Blatter, 2016).

At the surface of the ice sheet, atmospheric temperature is applied as a constant Dirichlet-type boundary condition, and at the base, GHF is included as a constant Neumann-type heat flux. A Weertman-type sliding law is implemented everywhere at the base. At regions with a frozen bed, sub-melt sliding is introduced following Hindmarsh and Le Meur (2001) to avoid singularity in the calculation of the velocity field at the transition between frozen and thawed bed regions. Frictional heating is included in the thermal boundary condition as the product of sliding velocity and basal shear stress (which in the case of SIA equals the driving stress).

We use a spatial resolution of $20 \mathrm{~km}$ which leads to a grid of $140 \times 82$ points in the stereographic plane. Sigma coordinates are used in the vertical direction $(z)$ : each ice column is mapped onto a $[0,1]$ interval, discretized by 81 vertical grid points. For modeling the thermal conduction in the underlying bedrock, we use 41 layers in the thermal lithosphere. The creep enhancement factor is chosen as a constant value of 1 for Holocene ice $(<11 \mathrm{ka})$ and 3 for Pleistocene ice (>11 ka) (similar to Greve, 2005; Rogozhina and others, 2012). The rest of the physical parameters are the same as those of Rückamp and others (2019, Table 1). Since the simulations are not in steady-state condition, a model for the glacial isostatic adjustment must be included to simulate the changes in bed elevation due to changes in the ice load. We use the Local-Lithosphere-Relaxing-Asthenosphere model (LLRA) with a time lag of 3000 years for relaxing the asthenosphere (following Le Meur and Huybrechts, 1996).

Input parameters to the model include average annual and monthly surface temperatures, annual surface mass balance, global sea level and GHF. Paleoclimate temperature variations across the ice sheet are modeled by implementing a time-dependent temperature anomaly function $\Delta T(t)$, such that

$$
\begin{aligned}
& T_{\mathrm{ma}}(S, \phi, \lambda, t)=T_{\mathrm{ma}}^{\text {present }}(S, \phi, \lambda)+\Delta T(t), \\
& T_{\mathrm{mj}}(S, \phi, \lambda, t)=T_{\mathrm{mj}}^{\text {present }}(S, \phi, \lambda)+\Delta T(t),
\end{aligned}
$$

where $T_{\mathrm{ma}}$ and $T_{\mathrm{mj}}$ represent present-day's mean annual and July temperatures (from Fausto and others, 2009); $\phi$ and $\lambda$ denote

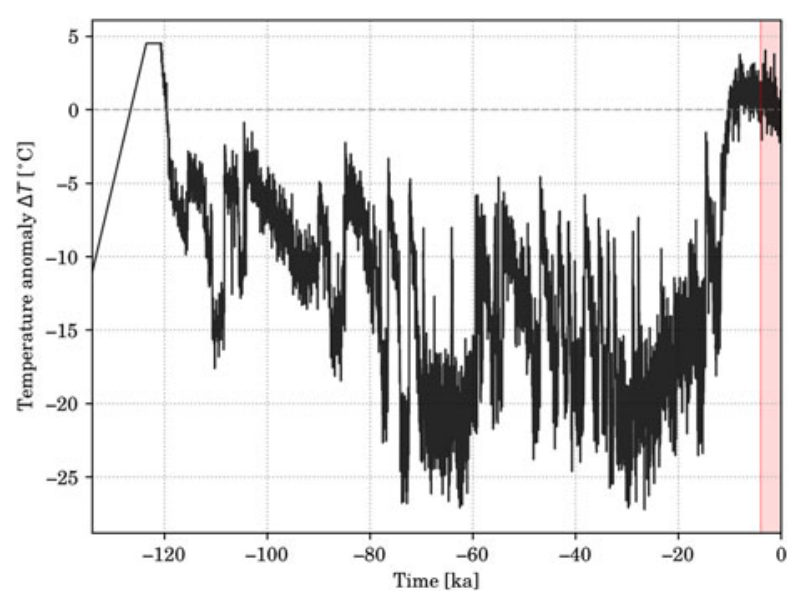

Fig. 2. Time series for the temperature anomaly $(\Delta T)$ used in Eqn (1). The last $4 \mathrm{ka}$ (light-red shading) are reconstructed from Kobashi and others (2011) while the rest of the anomaly is from the NorthGRIP ice core $\delta^{18} \mathrm{O}$ record (Andersen and others, 2004).

latitude and longitude, respectively, and $S$ is the surface elevation of the ice sheet. Temperature anomaly function is reconstructed using $\delta^{18} \mathrm{O}$ records from the NorthGRIP ice core since the last interglacial at $-120 \mathrm{ka}$ until $-4 \mathrm{ka}$ (Andersen and others, 2004). The time series is extended to the previous glacial maximum at $\sim-140 \mathrm{ka}$ by $\Delta T$ linearly decreasing to $-20^{\circ} \mathrm{C}$. From $-4 \mathrm{ka}$ to present, the reconstruction by Kobashi and others (2011) derived for the GISP2 site is used. The climate anomaly function is shown in Figure 2 and is spatially uniform.

We use monthly mean for present-day precipitation for the 1958-2001 period, obtained from the regional energy and moisture balance REMBO by Robinson and others (2010), provided with a spatial resolution of $100 \mathrm{~km}$. Following Huybrechts (2002), at every time step we assume $7.3 \%$ change in precipitation for a $1^{\circ} \mathrm{C}$ surface temperature change. Solid precipitation is calculated monthly using an empirical 5th order polynomial (Bales and others, 2009). We have used the positive degree day (PDD) parameterization from Reeh (1991) for estimating the surface melt with a semi-analytical solution for the PDD integral obtained by Calov and Greve (2005). For ice melt, the PDD factor $\beta_{\text {ice }}=8 \mathrm{~mm}$ w.eq. $\mathrm{d}^{-1}{ }^{\circ} \mathrm{C}^{-1}$ is used, while for snow melt $\beta_{\text {snow }}=$ $3 \mathrm{~mm}$ w.eq. $\mathrm{d}^{-1}{ }^{\circ} \mathrm{C}^{-1}$. For global sea level history, we use the reconstruction from the SPECMAP marine $\delta^{18} \mathrm{O}$ records provided by Imbrie and others (1984).

In numerical ice-sheet models, GHF is applied as a boundary condition to the thermal model, which itself is strongly tied to the mechanical model. Therefore, inversion for GHF in thermomechanically coupled ice-sheet models is very challenging. Studies have attempted to formulate and solve the inverse problem for GHF (e.g. Zhu and others, 2016). However, their analysis is limited to a cold ice sheet with a no-slip basal condition. This assumption makes their method unsuitable for the current study, because frictional heating is an important heat source especially near the margins of the ice sheet. Therefore, we apply an iterative scheme that incrementally adjusts the GHF in a forward model.

In this study, we start the paleoclimate simulations at $-134 \mathrm{ka}$ and all simulations are composed of three steps:

(1) First, the present-day geometry of GrIS provided by Bamber and others (2013) is relaxed for 100 years to create a smoothed geometry of the ice sheet.

(2) From -134 to $-9 \mathrm{ka}$, the ice sheet freely evolves given the initial and boundary conditions. The starting time of $-134 \mathrm{ka}$ is chosen because at that time $\Delta T=-11.3^{\circ} \mathrm{C}$, which is close to 
the mean temperature anomaly over the entire period. Basal sliding is gradually ramped up during the first $5 \mathrm{ka}$ of this step. This transitional period is required to avoid numerical stability problems, while being short enough not to influence the further evolution of the ice sheet significantly.

(3) From -9 ka to the present, the results of step (2) are used as initial conditions, and the computed ice-sheet topography (surface $S(x, y)$, bed $b(x, y))$ is continuously nudged toward the slightly smoothed present-day topography (surface $S_{\text {target }}(x, y)$, bed $\left.b_{\text {target }}(x, y)\right)$ produced by step (1). Starting the nudging process at $-9 \mathrm{ka}$ allows the ice sheet to evolve freely during the last glacial and the transition into the Holocene, thus preserving the paleo-climatic memory. For each time step, this nudging is done by first solving the normal evolution equations for the bed and the ice thickness (e.g. Greve and Blatter, 2009, Eqns (5.55) and (8.5)) and then applying the relaxation equations

$$
\begin{gathered}
\frac{\partial S}{\partial t}=-\frac{S-S_{\text {target }}}{\tau_{\text {relax }}}, \\
\frac{\partial b}{\partial t}=-\frac{b-b_{\text {target }}}{\tau_{\text {relax }}},
\end{gathered}
$$

with a relaxation time of $\tau_{\text {relax }}=100$ a (Rückamp and others, 2019). This is equivalent to applying an SMB correction (e.g. Calov and others, 2018), which is diagnosed by the model.

Because the goal is to estimate the GHF required to reach the bed to the pressure melting temperature, at the end of step (3) we check the basal thermal conditions at the locations of radardetected basal thaw: if $T_{\mathrm{b}}$ (relative to the pressure melting point) is colder than $-0.1{ }^{\circ} \mathrm{C}$, we increase the GHF by $5 \%$. Otherwise, if the basal melt rate $\dot{M}_{\mathrm{b}}$ at these locations is larger than $0.001 \mathrm{~m} \mathrm{a}^{-1}$, we decrease the GHF by $5 \%$. We terminate the simulations after 50 iterations of steps (1) through (3) when the majority of regions of interest have met the pressure melting point's criteria. Note that throughout the iterative procedure, we assume that basal water is due to basal melting at the same location (and not generated in other places and transported to that region), nor does it derive from surface or englacial water that has reached the bed (e.g. Poinar and others, 2015, 2017).

Since SICOPOLIS is thermo-mechanically coupled, the thermal properties at the locations where GHF is not adjusted impacts the flow field, and hence they impact the thermal properties of all regions. Therefore, we estimate $\mathrm{GHF}_{\mathrm{pmp}}$ for both radar detections of basal thaw, using five independent simulations with different initial GHF models; four simulations are with the GHF models shown in Figure 1, and one simulation with a spatially uniform GHF of $56 \mathrm{~mW} \mathrm{~m}^{-2}$ (denoted by U56, corresponding to the average GHF value of the North American plate, Sclater and others, 1980).

\subsection{Datasets for radar-detected basal thaw}

The spatial distribution of the basal thermal state is determined from two sources. The first dataset from Oswald and others (2018, hereafter OSW) is essentially based on the character of reflected radar signals from the ice-bed interface (after Oswald and Gogineni, 2008, 2012). Basal state determinations based on radar data (provided by Center for Remote Sensing of Ice Sheets, CReSIS during 1999-2003; Gogineni and others, 2001) are made approximately every $200 \mathrm{~m}$ along each radar flight line; melt detections are separated along the flight path by one ice thickness and the conditions for melting are assumed to be effectively continuous between melt detections. Circles are then drawn on the effectively continuous melting path segments, and an assumption of isotropy of the basal state distribution is used to infer the probable state across the flight path. This means that determinations from neighboring flight paths can be used in support of interpolated basal states and the effect of random detection errors is minimized. If two adjacent paths contradict each other, the priority is given to the non-ponded determinations. This technique allows for larger scale interpolation of the basal state of the ice, as opposed to narrow radar flight paths. The detected basal water using this method represents 'ponded' basal water that is thicker than $\sim 3 \mathrm{~cm}$. The rest of the regions could be frozen or temperate with a thinner layer of basal water. The spatial distribution of basal 'ponded water' from Oswald and others (2018) is shown in Figure 3a.

The second dataset is from Jordan and others (2018, hereafter JOR) who develop a new diagnostic method for inferring basal thermal state from radio echo sounding data. Their method, termed 'bed-echo reflectivity variability', uses bed-echo intensity and acts as an edge-detector to identify the locations where rapid transition between wet-dry bed occurs. Jordan and others (2018) show that their method is not affected by spatial variability in attenuation and can be adjusted to be used with different radar systems employed in different Operation IceBridge surveys. They interpret their results as 'basal water distribution' and every pick corresponds to a circle with $5 \mathrm{~km}$ diameter as the effective resolution of their method (see Jordan and others, 2018, Fig. 6). The spatial distribution of basal water from Jordan and others (2018) is shown in Figure 3b.

In order to implement the scattered radar points from the two datasets into a $20 \mathrm{~km}$ SICOPOLIS grid, we create polygons using individual radar picks from both studies (with an aggregate distance of $100 \mathrm{~km}$ ). Then, every SICOPOLIS grid point that falls within the created polygons are chosen as the targeted thawed points in SICOPOLIS. The aggregate distance of $100 \mathrm{~km}$ for creating the polygons is chosen after several experiments with different aggregate distances. This distance results in the best spatial representation of both radar datasets. Admittedly, this method over-interprets the locations of basal water, since not all the radar points in a $20 \mathrm{~km}$ pixel are necessarily inferred to be thawed using radar data. The uncertainties associated with such interpretation are discussed in Section 4.

The focus of this study is to set constraints on GHF based on the spatial distribution of thawed beds predicted by these two studies. Assessing the causes of the observed differences between the two datasets is beyond the scope and aim of the current work. However, it is worth mentioning that in both of these datasets, not detecting a thawed bed or ponded water does not indicate that the bed is frozen. Therefore, their differences are not necessarily contradictions; they rather show the strength or weakness of one of the radar techniques compared to the other.

\section{Results}

We calculate $\mathrm{GHF}_{\mathrm{pmp}}$ at the locations of basal thaw predicted by OSW and JOR separately. For each of these datasets, we perform five different simulations with all the GHF models considered in this study: at the locations where GHF is not being adjusted (referred to as 'background' GHF), the GHF values remain fixed as prescribed by each GHF model. Here we present the mean and standard deviation (STD) of all the GHF constraint estimates for both radar datasets (see Figs S1 and S2 for details of individual simulations with different background GHF values).

If the calculated GHF constraints are high, it is reasonable to ask whether frictional heating is responsible instead of a high GHF. In the majority of points where GHF is adjusted, a frozen 

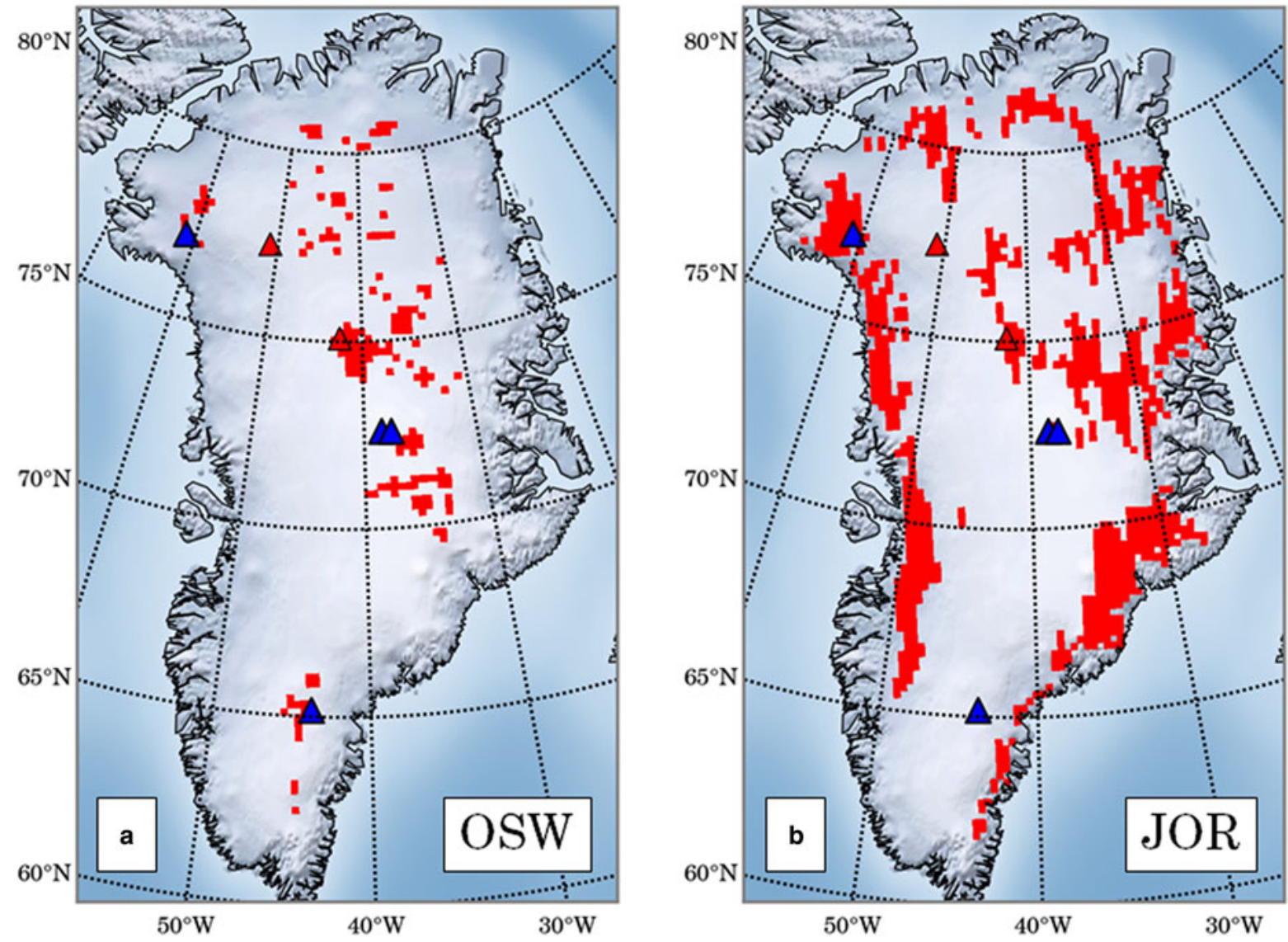

Fig. 3. Spatial distribution of radar-detected basal water from (a) Oswald and others (2018)-OSW, and (b) Jordan and others (2018)-JOR. The datasets provided by the two studies are grouped in $100 \mathrm{~km}$ polygons and then sampled at $20 \mathrm{~km}$ spacing to represent the spatial resolution of SICOPOLIS that is used in this study.

bed is switched to a thawed bed during the iterative process. This switching has resulted in an increase in both surface and basal sliding velocities compared with the initial state. This means that a previously frozen bed has become thawed after GHF adjustments, and even though the frictional heating is now added to the basal heat budget, the GHF constraint is still increased. Therefore, at the radar-points where GHF is adjusted, if the final basal velocity is increased (and consequently augmented the basal frictional heating) after GHF adjustments, our presented GHF constraints remain valid and our arguments hold.

On the other hand, it is possible that the final velocity after adjusting the GHF results in a lower surface and basal sliding velocity. This is more likely near the margins of the ice sheet where the interaction between fast flowing and slow moving ice becomes more complex. Interpreting the calculated GHF constraints becomes more challenging in such locations, because the portion of the adjusted GHF to reach the bed could have been due to the lowering of frictional heating. Frictional heating is a function of basal shear stress and sliding velocity, therefore, we investigated the regions where either of these two variables has decreased after the iterations (which has resulted in reduced frictional heating). Since this source of heat can be substantial in finding the GHF constraints, we remove the points with $G_{\text {friction-init }}-$ $G_{\text {friction-final }}<-5 \mathrm{~mW} \mathrm{~m}^{-2}$ for all simulations $\left(5 \mathrm{~mW} \mathrm{~m}^{-2}\right.$ subjectively assumed as a reasonable 'margin of error' for $\mathrm{GHF}_{\mathrm{pmp}}$ estimates). This ensures that the GHF constraints presented in the study are not 'contaminated' by the effect of decrease in frictional heating. Note that the offsets between the final modeled vs. present-day geometry are not sufficient to make a notable difference on changes in strain heating.

\section{1. $G H F_{p m p}$ at thawed points}

Figure 4 shows the estimated $\mathrm{GHF}_{\mathrm{pmp}}$ values, averaged for all five simulations at thawed-bed predictions by OSW (Fig. 4a) and JOR (Fig. 4c) (corresponding standard deviations, STD, shown in Figs $4 \mathrm{~b}, \mathrm{~d})$. Regardless of the 'background' GHF, the $\mathrm{GHF}_{\mathrm{pmp}}$ estimates are consistent for the majority of thawed regions.

For thawed points in the central-east region of OSW data, southeast of the GISP2 and GRIP ice cores, the average GHF $_{\mathrm{pmp}}$ is between 70 and $90 \mathrm{~mW} \mathrm{~m}^{-2}$ (Fig. 4a). Near the NGRIP ice core site, our estimates show that GHF of $\sim 70 \mathrm{~mW} \mathrm{~m}^{-2}$ is sufficient to thaw the bed. Slightly downstream of the NGRIP site toward the northeast region, $\mathrm{GHF}_{\mathrm{pmp}}$ is smaller with values near 40-50 $\mathrm{mW} \mathrm{m}^{-2}$. In the northwest region close to the Camp Century (CC) ice core site, despite the extent of basal thaw being rather small, the $\mathrm{GHF}_{\mathrm{pmp}}$ is relatively high with values greater than $85 \mathrm{~mW} \mathrm{~m}^{-2}$ (Fig. $4 \mathrm{a}$ ).

Because of the greater spatial extent of JOR dataset, the GHF constraints using this dataset contain more spatially detailed information. The GHF constraints in the northern parts of interior regions close to the NGRIP ice core site are within the range of 55-75 $\mathrm{mW} \mathrm{m}^{-2}$ (Fig. 4c). In contrast, the estimated $\mathrm{GHF}_{\mathrm{pmp}}$ decreases downstream of NGRIP toward the northeast region of the ice sheet and upstream of the 79North glacier to values as low as $10 \mathrm{~mW} \mathrm{~m}^{-2}$. These regions, despite having such low $\mathrm{GHF}_{\mathrm{pmp}}$ values still experience basal melt rates higher than our cut-off criterion (i.e. $\dot{M}_{\mathrm{b}}<0.001 \mathrm{~m} \mathrm{a}^{-1}$ ). The low $\mathrm{GHF}_{\mathrm{pmp}}$ values in the entire western flank of the ice sheet are similar to those of the downstream reaches of the northeast Greenland. Apart from a few scattered points, the low $\mathrm{GHF}_{\mathrm{pmp}}$ persists in the entire low-elevation regions in western Greenland. 

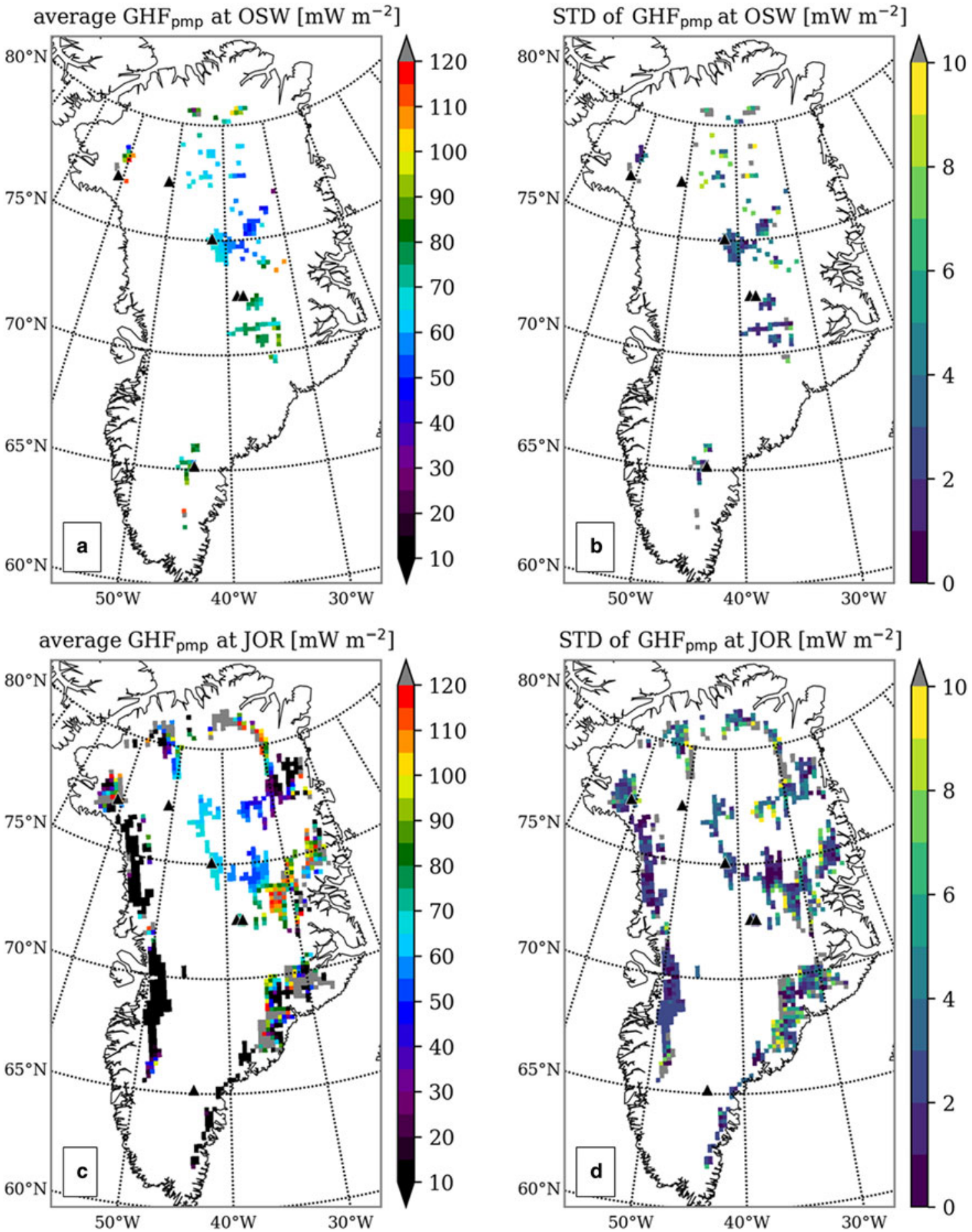

Fig. 4. Average and standard deviation (STD) of $\mathrm{GHF}_{\mathrm{pmp}}$ at basal thaw detections by OSW (a,b) and JOR (c,d). For GHF pmp values using individual GHF background maps, see Supplementary Figs S1 and S2.

In contrast to the low $\mathrm{GHF}_{\mathrm{pmp}}$ regions, two regions stand out for having a notably high $\mathrm{GHF}_{\mathrm{pmp}}$ values using the JOR dataset. In central-east and northern parts of the GrIS, $\mathrm{GHF}_{\mathrm{pmp}}$ values as high as $100-120 \mathrm{~mW} \mathrm{~m}^{-2}$ are estimated (Fig. 4c). At several of these points, the cut-off criterion for basal temperature relative to the pressure melting point (i.e. $T_{\mathrm{b}}>-0.1^{\circ} \mathrm{C}$ ) was not achieved and the simulation was terminated after 50 iterations (see Section 2.1).

\subsection{Simplified sensitivity analysis}

The results presented here contain paleoclimate simulations that are enforced based on climate reconstructions of ice cores and marine $\delta^{18} \mathrm{O}$ records. Therefore, they carry uncertainties that can alter the present results. Given the computational expense of the iterative simulations presented here, performing sensitivity analysis on climatic parameters is extremely costly. Therefore, we analyze the sensitivity of $\mathrm{GHF}_{\mathrm{pmp}}$ estimates at several anomalous locations with a 1D analytical solution of the temperature profile of ice sheets. We use the solution provided by Rezvanbehbahani and others (2019b) which is an improvement to the Robin (1955) analytical solution and allows estimating the $\mathrm{GHF}_{\mathrm{pmp}}$ given the surface temperature, ice thickness and surface mass-balance rate. Although the solution is obtained in steady-state conditions (unlike the SICOPOLIS simulations presented here), it facilitates analyzing the sensitivity of GHF 

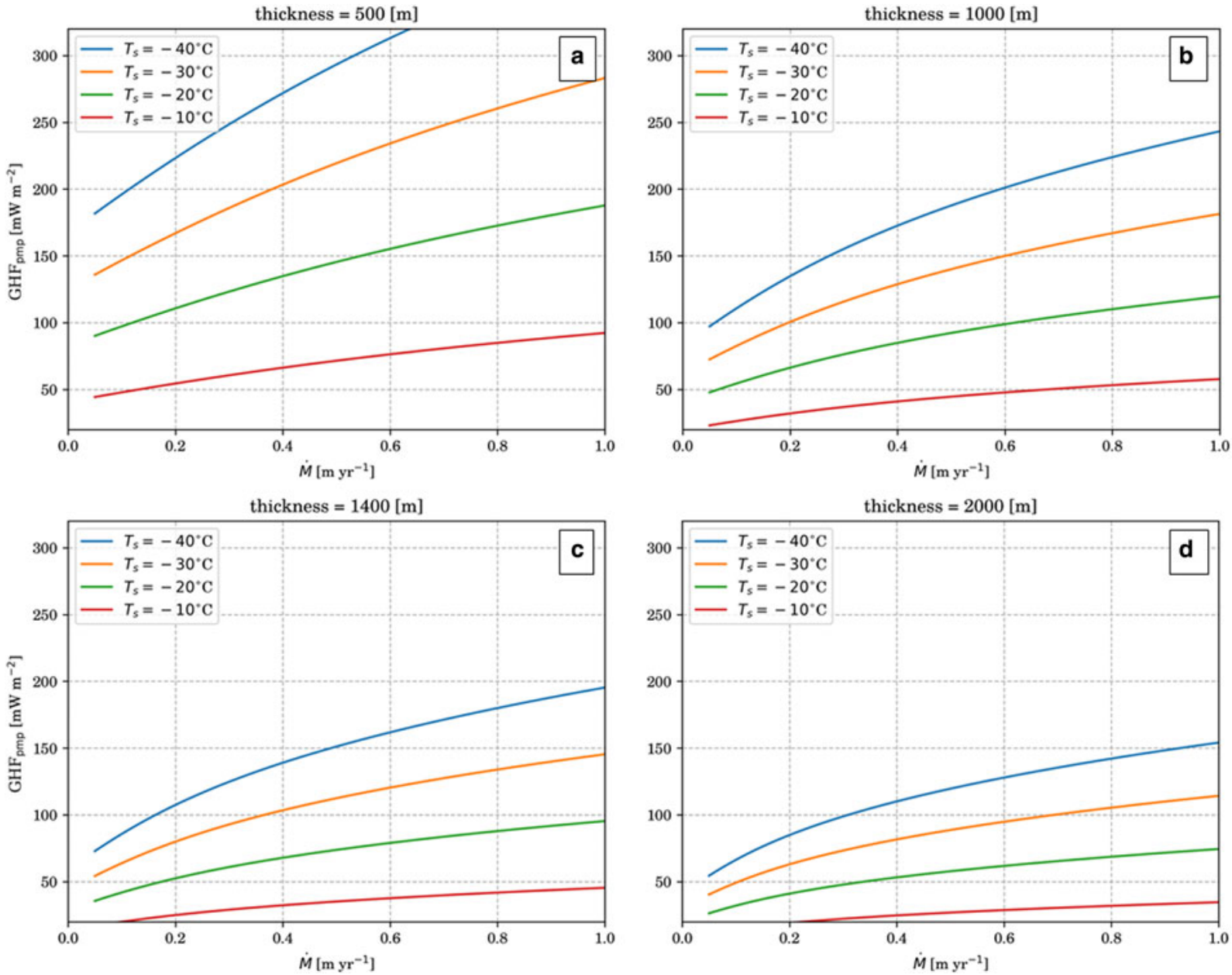

Fig. 5. $\mathrm{GHF}_{\mathrm{pmp}}$ calculated from the $1 \mathrm{D}$ analytical solution provided by Rezvanbehbahani and others (2019b). The GHF $\mathrm{pmp}_{\mathrm{p}}$ is calculated for four thickness values of (a) $500 \mathrm{~m}$, (b) $1000 \mathrm{~m}$, (c) $1400 \mathrm{~m}$ and (d) $2000 \mathrm{~m}$ and a range of surface temperature values $T_{\mathrm{s}}$ from -10 to $-40^{\circ} \mathrm{C}$. The $x$-axis represents the surface mass balance, $\dot{M}$. The thickness ranges of (a) and (b) are chosen to represent the central-east region of the GrIS, while (c) is chosen to represent the CC ice core, and (d) represents the Dye-3 ice core.

constraints on a wider range of climatic variables. We assess the sensitivity of high $\mathrm{GHF}_{\mathrm{pmp}}$ estimates near CC, Dye-3 and central-east regions of the GrIS.

The CC and Dye-3 ice cores are near ice divides and the horizontal velocities are small. Therefore, the conditions are suitable to use a $1 \mathrm{D}$ analytical solution for the vertical temperature near this site. Thickness of the CC and Dye-3 ice cores is $\sim 1400$ and $2000 \mathrm{~m}$, respectively. In the central-east region of the ice sheet where the $\mathrm{GHF}_{\mathrm{pmp}}$ estimates from SICOPOLIS are high, thickness values range from a few hundred to $\sim 1000 \mathrm{~m}$. Because the analytical solution is in steady-state, we use a range of input variables for surface mass-balance rate and surface temperature to calculate the $\mathrm{GHF}_{\mathrm{pmp}}$.

During the 1960-1990 period (during which net accumulation matched the net ablation, Van den Broeke and others, 2009), the surface mass balance from regions obtained from RACMO2/GR (Ettema and others, 2010) ranges between $\sim 0.4$ and $0.8 \mathrm{~m} \mathrm{a}^{-1}$ ice equivalent with surface temperatures $\sim-30$ to $-20^{\circ} \mathrm{C}$ for all the three regions of interest. We use a wider range of surface mass-balance rate values $\left(0.1-1 \mathrm{~m} \mathrm{a}^{-1}\right)$, as well as surface temperatures ranging from -40 to $-10^{\circ} \mathrm{C}$.

The $\mathrm{GHF}_{\mathrm{pmp}}$ calculations from the 1D analytical solution are shown in Figure 5; Figures 5a, b represent the central-east regions; Figures $5 c, d$ correspond to CC and Dye- 3 ice core regions, respectively. This simple sensitivity analysis confirms that the central-east region requires a significantly higher GHF to thaw the bed. It also shows that at the CC ice core site, where
RACMO2/GR reports surface temperature of $-25^{\circ} \mathrm{C}$ and surface mass-balance rate of $\sim 0.4 \mathrm{~m} \mathrm{a}^{-1}$, the GHF value of roughly $90 \mathrm{~mW} \mathrm{~m}^{-2}$ is needed to thaw the bed (Fig. 5c). The value of $\mathrm{GHF}_{\mathrm{pmp}}$ is $\sim 60 \mathrm{~mW} \mathrm{~m}^{-2}$ for Dye-3 with surface mass-balance rate of $\sim 0.65 \mathrm{~m} \mathrm{a}^{-1}$ and surface temperature of $-19^{\circ} \mathrm{C}$. Considering that both these ice cores have measured basal temperatures $\sim-13^{\circ} \mathrm{C}$, the actual GHF is likely much less than $\mathrm{GHF}_{\mathrm{pmp}}$ estimates in this section.

\subsection{Comparing $\mathrm{GHF}_{p m p}$ vs. GHF models}

The GHF constraints calculated here are the lower limits of GHF to produce basal thaw, so the GHF models must be larger than the constraints if they are to properly simulate the detections of basal thaw. Figure 6 shows the spatial differences between $\mathrm{GHF}_{\mathrm{pmp}}$ and GHF models at locations of basal thaw for both radar datasets, and Figure 7 is a scatter representation of such differences. Because the uncertainties in all GHF models are relatively high, the 'acceptable' range for GHF models is chosen such that

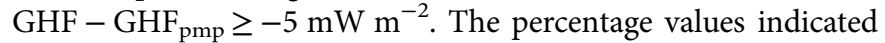
on each map in Figure 6 shows the ratio of the points in each GHF map that are acceptable with respect to the estimated GHF constraints.

There are several locations where the GHF models satisfy their lowest constraint imposed by $\mathrm{GHF}_{\mathrm{pmp}}$. The most notable of all are the downstream regions of almost the entire western margin of the ice sheet where JOR dataset predicts extensive basal thaw. 

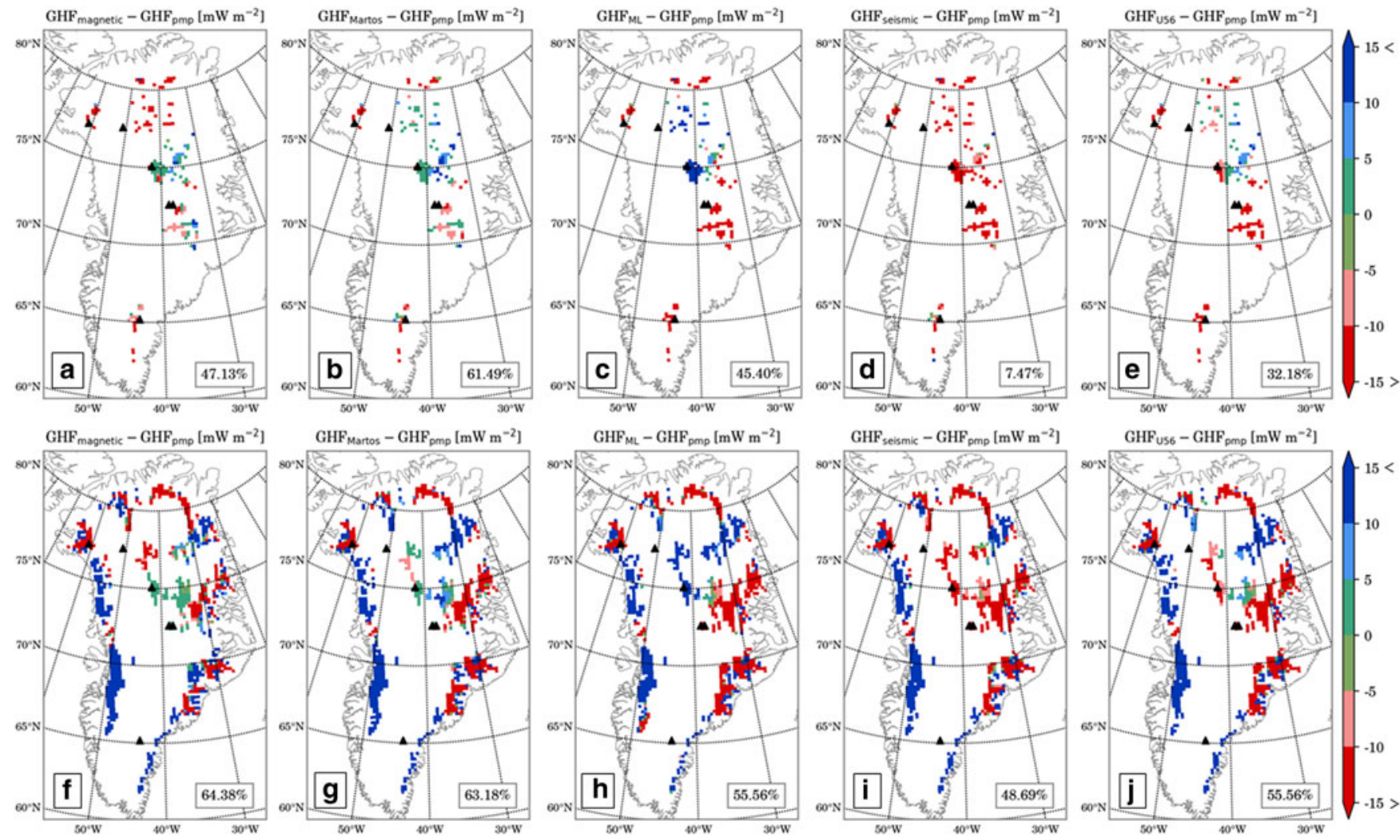

Fig. 6. Comparing the $\mathrm{GHF}_{\mathrm{pmp}}$ estimates at thawed points of OSW (a-e) and JOR ( $\left.f-j\right)$ with respect to different GHF maps. The percentage values in each panel shows the ratio of points in each GHF map that are 'acceptable' according to the estimates constraints defined as (\#of points with $\mathrm{GHF}_{-}-\mathrm{GHF}_{\mathrm{pmp}} \geq-5 \mathrm{~mW} \mathrm{~m}^{-2}$ )/ \#total points.
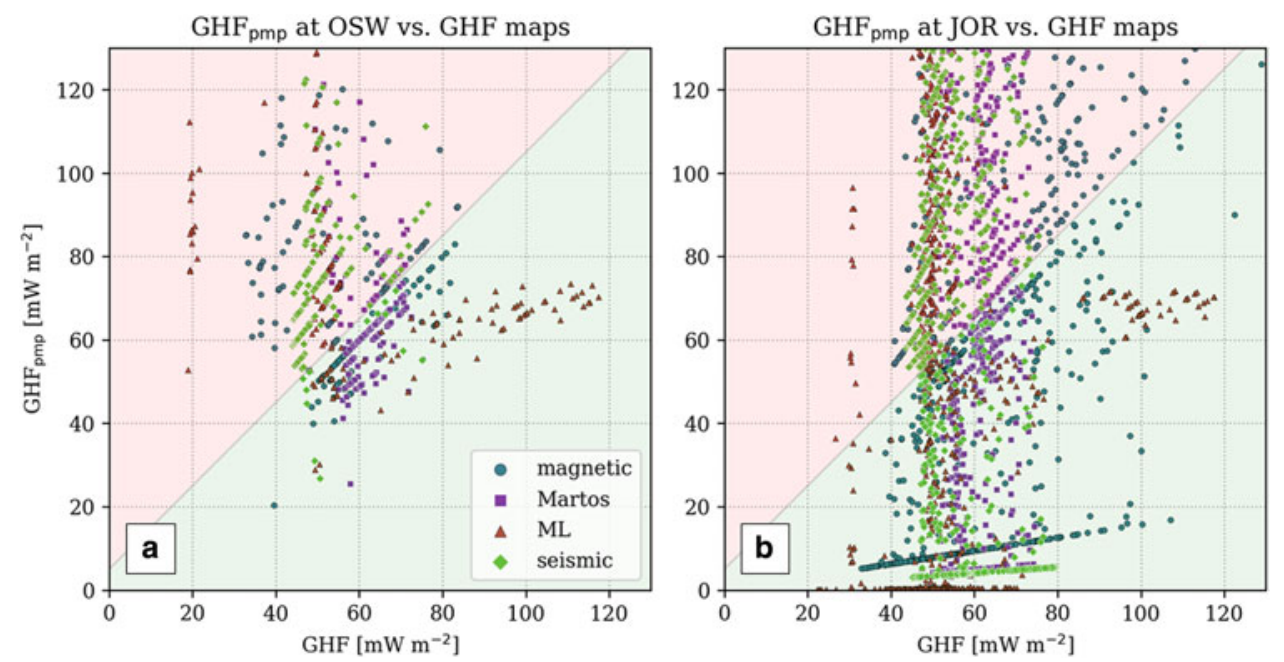

Fig. 7. Difference between the GHF maps ( $x$-axis) and calculated GHF constraints ( $y$-axis). The green region is where $\mathrm{GHF}_{-}-\mathrm{GHF}_{\mathrm{pmp}} \geq-5 \mathrm{~mW} \mathrm{~m}^{-2}$, as the 'acceptable' difference with respect to the calculated constraints.

Our estimated GHF constraints are very small and all GHF models satisfy the constraints. Other notable regions are the northeast of the NGRIP ice core (from OSW dataset) and approximate location of the downstream of NEGIS upstream of 79North glacier (from JOR dataset).

In contrast, however, several regions from both datasets result in very high GHF constraints that are not satisfied in any of the GHF models. The most prominent one is the central-east region at $30^{\circ} \mathrm{W}, 70^{\circ} \mathrm{N}$ and to the north at $\sim 30^{\circ} \mathrm{W}, 73^{\circ} \mathrm{N}$. The values from GHF models in this region are substantially smaller than the required heat flux to thaw the bed. Other regions of disagreement are around the CC ice core (from both radar datasets), scattered points near Dye-3 (Figs 6a-e), and the northern margin of the ice sheet (Figs $6 \mathrm{f}-\mathrm{j}$ ).

\section{Discussion}

\subsection{GHF constraints and ice core data}

There are regions of basal thaw in the central-east catchment of the ice sheet where the $\mathrm{GHF}_{\mathrm{pmp}}$ values are estimated to be very high. There are no deep ice cores in this area to confirm or reject such high GHF estimates. Nearly all GHF models predict elevated GHF values in the eastern edge of Greenland (at $70^{\circ} \mathrm{N}, 30^{\circ} \mathrm{W}$, 
Fig. 1), but except for the magnetically-derived GHF map of Fox Maule and others (2009), none of the maps predict GHF values as high as $100 \mathrm{~mW} \mathrm{~m}^{-2}$. Although several of the current GHF models predict a high heat flux in the eastern regions (along the trajectory of Icelandic plume), only the GHF reconstruction of Rogozhina and others (2016) and more recently Artemieva (2019) predict GHF values as high as $100 \mathrm{~mW} \mathrm{~m}^{-2}$ in east Greenland. This region is suggested to have lower lithosphere viscosity as well as a higher temperature compared to the rest of the cratonic settings in Greenland (Mordret, 2018). Therefore, the extensive basal thaw in the central-east region may be associated with GHF variations due to the remnant of the Icelandic plume.

The basal temperature at the GISP2 and GRIP ice core sites are reportedly cold at $\sim-9^{\circ} \mathrm{C}$ (Dahl-Jensen and others, 1998). Both radar datasets detect water a few tens of kilometers to the east of these ice cores. The GHF to match the basal temperature measurements at the GRIP ice core site is $51 \mathrm{~mW} \mathrm{~m}^{-2}$ (Greve, 2019). The value of $\mathrm{GHF}_{\mathrm{pmp}}$ at the basal thaw determinations in these regions is estimated to be close to the continental average $\left(\sim 70 \mathrm{~mW} \mathrm{~m}^{-2}\right)$. Given that the distance between GRIP/GISP2 ice core sites and the closest cluster of basal water determinations from the two datasets is $\sim 30-40 \mathrm{~km}$, we suggest that the observed basal thaw in this region can be associated to spatial variations in the GHF.

Radar determinations of basal thaw or ponded water near Dye-3 and CC ice core sites are rather surprising. The basal temperatures at Dye- 3 and CC ice cores are both near $-13^{\circ} \mathrm{C}$ (Dansgaard and others, 1969; Gundestrup and Hansen, 1984), far below the pressure melting temperature. The matching GHF to reproduce these basal temperatures in SICOPOLIS are $32 \mathrm{~mW} \mathrm{~m}^{-2}$ for Dye- 3 and $47 \mathrm{~mW} \mathrm{~m}^{-2}$ for CC (Greve, 2019). Our results show that $\mathrm{GHF}_{\mathrm{pmp}}$ ranges between 70 and $90 \mathrm{~mW} \mathrm{~m}^{-2}$ near Dye-3 and is over $100 \mathrm{~mW} \mathrm{~m}^{-2}$ near the CC ice core site (Fig. 4). Comparison between the GHF models and estimated $\mathrm{GHF}_{\mathrm{pmp}}$ shows that neither of the GHF models predict such high GHF values in these regions (see Section 3.3). The closest cluster of basal thaw determinations from Jordan and others (2018) dataset is $\sim 5 \mathrm{~km}$ away from the CC ice core and the closest cluster of ponded water from Oswald and others (2018) is more than $10 \mathrm{~km}$ away. While there is no standard expected length-scale for spatial variations in GHF, it is unlikely that GHF can vary so drastically in such small spatial scales $(<10 \mathrm{~km})$. The contrast between the GHF at ice cores and $\mathrm{GHF}_{\mathrm{pmp}}$ in close vicinity of the core sites indicates that the basal thermal conditions could vary over much shorter spatial scales than commonly assumed.

\subsection{Possible mechanisms for local GHF variations}

The apparent contradiction between detection of basal thaw from radar data and very low basal temperatures from ice cores cannot be reconciled without considering other local mechanisms that can alter the local heat flux at the bed. The first mechanism is suggested by Van der Veen and others (2007) who show that variations in topography (such as troughs and valleys) alter the local GHF so that topographic lows experience enhanced heat fluxes at edges, while the topographic highs have lower heat flux peaks. Given the rough nature of subglacial topography (especially in the central-east regions, Rippin, 2013; Rezvanbehbahani and others, 2019a), it is possible that such high GHF fluctuations do actually occur at such small spatial scales $(<10 \mathrm{~km})$.

The second possible explanation is hydrothermal circulation that can augment the basal heat flux due to the interaction of subglacial groundwater and basal ice. The modeling study by Gooch and others (2016) suggests that during the retreat phase of ice sheets, the vertical water discharge from sedimentary aquifers in the subglacial environment can add to the net heat budget at the base of the ice sheet. In Greenland, geophysical surveys have identified regions of saturated till at the bed (e.g. Christianson and others, 2014); but the study of subglacial aquifers has gained little attention. These two mechanisms, however, occur at a much smaller spatial scale than the GHF models presented here. Therefore, special attention should be dedicated to small-scale processes that can result in significant and short-scale variations of GHF.

The third mechanism to elevate the GHF is due to the vugwave' fluid migration processes (PhippsMorgan and Holtzman, 2005); due to the loading and unloading during the glacial and inter-glacial phases, Stevens and others (2016) show that molten magma at depth can migrate through faults and dyke emplacement which can substantially augment the basal heat flux. This mechanism is hypothesized to alter the Greenland's heat flux on a substantially larger scale and impact the overall stability of the GrIS (Alley and others, 2019).

Our results indicate that the lower elevation regions of western Greenland, even with low GHF values of $10 \mathrm{~mW} \mathrm{~m}^{-2}$, undergo substantial basal thaw (Figs 4 and $6 f-j$ ). This indicates that there is a very high certainty that these regions are almost entirely temperate. However, the analysis of radar data does not show a continuous determination of basal water (see Jordan and others, 2018, Fig. 6; Oswald and others, 2018, Fig. 11). Our findings demonstrate that the extent of basal thaw in these regions is significantly larger than what is inferred from radar data. This confirms Jordan and others (2018)'s note that their criterion for basal thaw is necessary but insufficient (and that their results only show 'rapid spatial transitions' in basal condition). Similarly, it is possible that rapid drainage of the basal water or the shallow depth of basal water prevents ponded water detections by Oswald and others (2018) method. We suggest that this region can serve as a proper location for improving the analysis of radar data, because according to the analysis presented here, it is likely extensively thawed at the bed.

\subsection{Catchment-wide $\dot{M}_{\mathrm{b}}$ estimates}

The GHF models for Greenland analyzed in this study bear almost no resemblance to each other (Fig. 1). Without direct borehole measurements and some indirect geologic and glaciologic proxies (e.g. the onset location of the Northeast Greenland Ice Stream, NEGIS, or the possible trajectory of the Icelandic plume), there is no straightforward way to confirm or reject the current models. These GHF models undoubtedly lead to different spatial distributions of basal thaw in Greenland (e.g. Rogozhina and others, 2012). It is crucial, however, to investigate whether these different models and their 'modified' versions (which include the $\mathrm{GHF}_{\mathrm{pmp}}$ estimates in this study) result in substantial differences in terms of the amount of basal water generated in Greenland.

In order to evaluate the impact of GHF differences and the calculated constraints on the net basal melt rate in Greenland, we calculate the annual rate of basal melt-water produced in each catchment of Greenland with a) all five GHF maps (as in Fig. 1 and U56), (b) modified GHF models in Figure 1 by setting the GHF values to $\mathrm{GHF}_{\mathrm{pmp}}$ at the regions of disagreement (Section 3.3) according to OSW dataset, and (c) same as case (b) but modified according to the distribution of JOR dataset. In other words, the 'modified' GHF maps are $\mathrm{GHF}_{\text {mod }}=\max \left(\mathrm{GHF}, \mathrm{GHF}_{\mathrm{pmp}}\right)$.

Comparison between the values of total basal melt rate shows that although the spatial distribution of temperate bed may vary substantially depending on the GHF model, the total magnitude of basal melt-water remains relatively unchanged (Table S1). The net basal melt rate of GrIS using different GHF models is $\sim 15-20 \mathrm{~km}^{3} \mathrm{a}^{-1}$, substantially smaller than the range of surface 
mass loss in Greenland (Fettweis and others, 2013; Csathó and others, 2014). However, it has important implications for estimating the continuous year-round discharge from the base of outlet glaciers. It is worth noting that since we have not included a subglacial hydrology model (e.g. de Fleurian and others, 2018; Sommers and others, 2018), our estimates do not take into account the interactions between subglacial hydrological network and GHF. Such interactions can alter the ice velocity and may consequently change the basal thermal regime of the ice sheet. This may be a topic for future studies.

\subsection{Modeling shortcomings and radar uncertainties}

Throughout the iterative procedures in all the simulations of this study, the aim has been to keep the GrIS geometry intact. Because the iterations using Oswald and others (2018) dataset involved fewer points, the geometry and surface velocity has been reconstructed relatively well (Fig. S1). However, the spatial extent of the basal thaw based on Jordan and others (2018) is much larger. Therefore, the substantial adjustments to the GHF have resulted in altering the geometry of the ice sheet; these alterations are more notable toward the margins and insignificant in the interior regions (Fig. S2). Due to thermo-mechanical coupling of the ice flow, local enhancement of GHF changes the flow and geometry, specifically in the low-velocity regions (Pittard and others, 2016). Changes in the velocity profile of the ice sheet alter the rate of advection from upstream, therefore altering the thermal field of the neighboring points. Therefore, it is not surprising that the $\mathrm{GHF}_{\mathrm{pmp}}$ based on either OSW or JOR datasets varies depending on the initial choice of GHF map.

The effective resolution of JOR dataset is $\sim 5 \mathrm{~km}$, and the internal consistency method of OSW results are provided in $1 \mathrm{~km}$ spatial scale. Due to the high computational cost of performing the iterative procedure in $5-10 \mathrm{~km}$ spatial resolution, we clustered the locations of basal thaw from the two datasets into $20 \mathrm{~km}$ spatial resolution. This clustering is an exaggeration of the extent of thaw for both basal water datasets. The determinations of temperate basal ice from the radar data could be associated to enhanced localized heat flux (e.g. Van der Veen and others, 2007) or a complex distribution of subglacial water (e.g. Schroeder and others, 2013; Chu and others, 2018; Bowling and others, 2019). In order to reconstruct such small-scale details of basal heat and direction of subglacial water flow, higher resolution models coupled with a dynamic hydrologic component must be considered (e.g. Dow and others, 2018).

In all the presented results, we have neglected the uncertainties in thaw determinations from radar data. Analyses of the radar bed-echo characteristics are not unique; it is possible that the thaw interpretations can actually be due to variations in basal roughness, or a combination of basal thaw and roughness variations. Therefore, additional research must be conducted to enable the differentiation of basal roughness variations and regions of basal thaw from radar data.

\section{Conclusion}

We use the locations of basal water in Greenland, detected by two radar datasets to constrain the GHF in Greenland using SICOPOLIS numerical model. The GHF at these locations is iteratively adjusted so that the basal temperature or basal melt rates become near zero, hence finding the minimum GHF that is required to reach the bed to the pressure melting point $\left(\mathrm{GHF}_{\mathrm{pmp}}\right)$. We conduct the iterative simulations with different initial GHF models of Greenland to resolve the uncertainty associated with the initial basal thermal condition on the final constraints. Although there are locations whose GHF constraints differ depending on the initial GHF model, there are persistent regions where the constraints are anomalously high or low. The most prominent regions with anomalously low $\mathrm{GHF}_{\mathrm{pmp}}$ values include a large part of the low-elevation regions of the western flank of the ice sheet, as well as in the northeast region, downstream of NEGIS.

We find several regions with $\mathrm{GHF}_{\mathrm{pmp}}$ values as high as $100 \mathrm{~mW} \mathrm{~m}^{-2}$. The largest region with high $\mathrm{GHF}_{\mathrm{pmp}}$ is in the central-east of the ice sheet, to the east of GISP2 and GRIP ice cores; in all simulations the estimated $\mathrm{GHF}_{\mathrm{pmp}}$ is $\sim 100$ $120 \mathrm{~mW} \mathrm{~m}^{-2}$. Our results also highlight sharp contrasts between low basal temperature readings from CC and Dye- 3 ice cores and prediction of basal water by both radar datasets. We argue that the existence of water in close proximity to these ice cores cannot be explained by the spatial variability of GHF; we posit that such sharp contrasts can be better explained by the effect of elevated heat flux near the topographic edges (Van der Veen and others, 2007), the interplay between glacial loading and volcanism in the underlying crust (Stevens and others, 2016; Alley and others, 2019), or the discharge of groundwater aquifers into the subglacial environment and elevating the basal heat flux (Gooch and others, 2016). These mechanisms are not currently incorporated in GHF or glaciologic models and can help resolve the current discrepancies between modeled and observed basal thermal state of the GrIS. Finally, we show that despite all these differences in GHF maps and uncertainties in reconciling observations with our model, the net basal melt-water production does not significantly differ depending on the GHF model.

Supplementary material. To view supplementary material for this article, please visit https://doi.org/10.1017/jog.2019.79

Acknowledgments. We thank Thomas Jordan for providing the data for basal thaw detection, Michiel van den Broeke for the RACMO2 dataset and Gunter Leguy for insightful discussions. We also thank scientific editor Frank Pattyn and two anonymous reviewers for their constructive comments that greatly improved the clarity of this manuscript. S.R. was supported by the NSF grant ANT0424589, L.A.S. was supported by the NASA grant NNX10AP05G and C.J.V. was supported by the NSF grant ARC0909422. G.K.A.O. acknowledges NSF ARRA Grant 0909431, by the University of Maine Climate Change Institute. R.G. was supported by the Japan Society for the Promotion of Science (JSPS) through KAKENHI grant numbers JP16H02224 and JP17H06104, and by the Japanese Ministry of Education, Culture, Sports, Science and Technology (MEXT) through the Arctic Challenge for Sustainability (ArCS) project.

\section{References}

Alley RB and 9 others (2019) Possible role for tectonics in the evolving stability of the Greenland Ice Sheet. Journal of Geophysical Research: Earth Surface 124(1), 97-115. doi: 10.1029/2018JF004714

Andersen KK and 9 others (2004) High-resolution record of Northern Hemisphere climate extending into the last interglacial period. Nature 431(7005), 147. doi: $10.1038 /$ nature 02805

Artemieva IM (2019) Lithosphere thermal thickness and geothermal heat flux in Greenland from a new thermal isostasy method. Earth-Science Reviews 188, 469-481. ISSN 0012-8252. doi: 10.1016/j.earscirev.2018.10.015

Aschwanden A, Bueler E, Khroulev C and Blatter H (2012) An enthalpy formulation for glaciers and ice sheets. Journal of Glaciology 58(209), 441-457. doi: 10.3189/2012JoG11J088

Bales RC and 8 others (2009) Annual accumulation for Greenland updated using ice core data developed during 2000-2006 and analysis of daily coastal meteorological data. Journal of Geophysical Research: Atmospheres 114(D6), D06116. doi: 10.1029/2008JD011208

Bamber JL and 10 others (2013) A new bed elevation dataset for Greenland. The Cryosphere 7(2), 499-510. doi: 10.5194/tc-7-499-2013

Blatter H and Greve R (2015) Comparison and verification of enthalpy schemes for polythermal glaciers and ice sheets with a one-dimensional model. Polar Science 9(2), 196-207. doi: 10.1016/j.polar.2015.04.001 
Bowling J, Livingstone SJ, Sole AJ and Chu W (2019) Distribution and dynamics of greenland subglacial lakes. Nature Communications 10, 2810. doi: 10.1038/s41467-019-10821-w

Calov R and 8 others (2018) Simulation of the future sea level contribution of Greenland with a new glacial system model. The Cryosphere 12, 3097-3121. doi: $10.5194 /$ tc-12-3097-2018

Calov R and Greve R (2005) A semi-analytical solution for the positive degree-day model with stochastic temperature variations. Journal of Glaciology 51(172), 173-175. doi: 10.3189/172756505781829601

Christianson K and 7 others (2014) Dilatant till facilitates ice-stream flow in northeast Greenland. Earth and Planetary Science Letters 401, 57-69. doi: 10.1016/j.epsl.2014.05.060

Chu W, Schroeder DM, Seroussi H, Creyts TT and Bell RE (2018) Complex basal thermal transition near the onset of Petermann Glacier, Greenland. Journal of Geophysical Research: Earth Surface 123(5), 985-995. doi: 10. 1029/2017JF004561

Csathó B and 9 others (2014) Laser altimetry reveals complex pattern of Greenland Ice Sheet dynamics. Proceedings of the National Academy of Sciences 111(52), 18478-18483. doi: 10.1073/pnas.1411680112

Dahl-Jensen D and 6 others (1998) Past temperatures directly from the Greenland Ice Sheet. Science 282(5387), 268-271. doi: 10.1126/science. 282.5387.268

Dahl-Jensen D, Gundestrup N, Gogineni SP and Miller H (2003) Basal melt at NorthGRIP modeled from borehole, ice-core and radio-echo sounder observations. Annals of Glaciology 37(1), 207-212. doi: 10.3189/172756403781815492

Dansgaard W, Johnsen SJ, Møller J and Langway CC (1969) One thousand centuries of climatic record from Camp Century on the Greenland Ice Sheet. Science 166(3903), 377-380. doi: 10.1126/science.166.3903.377

de Fleurian B and 9 others (2018) SHMIP The subglacial hydrology model intercomparison Project. Journal of Glaciology 64(248), 897-916. doi: 10 1017/jog.2018.78

Dow CF and 6 others (2018) Dynamics of active subglacial lakes in Recovery Ice Stream. Journal of Geophysical Research: Earth Surface 123(4), 837-850. doi: 10.1002/2017JF004409

Ettema J and 5 others (2010) Climate of the Greenland Ice Sheet using a highresolution climate model-Part 1: evaluation. The Cryosphere 4(4), 511-527. doi: 10.5194/tc-4-511-2010

Fahnestock M, Abdalati W, Joughin I, Brozena J and Gogineni P (2001) High geothermal heat flow, basal melt, and the origin of rapid ice flow in central Greenland. Science 294(5550), 2338-2342. doi: 10.1126/science.1065370

Fausto RS, Ahlstrøm AP, Van As D, Bøggild CE and Johnsen SJ (2009) A new present-day temperature parameterization for Greenland. Journal of Glaciology 55(189), 95-105. doi: 10.3189/002214309788608985

Fettweis $\mathbf{X}$ and 6 others (2013) Estimating the greenland ice sheet surface mass balance contribution to future sea level rise using the regional atmospheric climate model MAR. The Cryosphere 7(2), 469-489. doi: 10.5194/tc-7-469-2013

Fox Maule C, Purucker ME and Olsen N (2009) Inferring magnetic crustal thickness and geothermal heat flux from crustal magnetic field models. Danish Climate Centre Report, 09-09.

Glen JW (1955) The creep of polycrystalline ice. Proceedings of the Royal Society of London. Series A. Mathematical and Physical Sciences 228(1175), 519-538. doi: 10.1098/rspa.1955.0066

Gogineni S and 9 others (2001) Coherent radar ice thickness measurements over the Greenland Ice Sheet. Journal of Geophysical Research: Atmospheres 106(D24), 33761-33772. doi: 10.1029/2001JD900183

Gooch BT, Young DA and Blankenship DD (2016) Potential groundwater and heterogeneous heat source contributions to ice sheet dynamics in critical submarine basins of East Antarctica. Geochemistry, Geophysics, Geosystems 17(2), 395-409. doi: 10.1002/2015GC006117

Goossens T and 5 others (2016) A comprehensive interpretation of the NEEM basal ice build-up using a multi-parametric approach. The Cryosphere 10 (2), 553-567. doi: 10.5194/tc-10-553-2016

Greve R (1997) Application of a polythermal three-dimensional ice sheet model to the Greenland Ice Sheet: Response to steady-state and transient climate scenarios. Journal of Climate 10(5), 901-918. doi: 10.1175/ 1520-0442(1997)010<0901:AOAPTD>2.0.CO;2

Greve R (2005) Relation of measured basal temperatures and the spatial distribution of the geothermal heat flux for the Greenland Ice Sheet. Annals of Glaciology 42(1), 424-432. doi: 10.3189/172756405781812510

Greve R (2019) Geothermal heat flux distribution for the Greenland Ice Sheet, derived by combining a global representation and information from deep ice cores. Polar Data Journal 3, 22-36. doi: 10.20575/00000006
Greve R and Blatter H (2009) Dynamics of Ice Sheets and Glaciers. Berlin, Germany: Springer Science \& Business Media. doi: 10.1007/978-3-642-03415-2

Greve R and Blatter H (2016) Comparison of thermodynamics solvers in the polythermal ice sheet model SICOPOLIS. Polar Science 10(1), 11-23. doi: 10.1016/j.polar.2015.12.004

Greve R and Hutter K (1995) Polythermal three-dimensional modelling of the Greenland Ice Sheet with varied geothermal heat flux. Annals of Glaciology 21, 8-12. doi: 10.3189/S0260305500015524

Gundestrup NS and Hansen BL (1984) Bore-hole survey at Dye 3, south Greenland. Journal of Glaciology 30(106), 282-288. doi: 10.3189/ S0022143000006109

Hindmarsh RCA and Le Meur E (2001) Dynamical processes involved in the retreat of marine ice sheets. Journal of Glaciology 47(157), 271-282. doi: 10. 3189/172756501781832269

Hutter K (1983) Theoretical Glaciology: Material Science of Ice and the Mechanics of Glaciers and Ice Sheets, volume 1. Dordrecht: Springer. doi: 10.1007/978-94-015-1167-4

Huybrechts P (2002) Sea-level changes at the LGM from ice-dynamic reconstructions of the Greenland and Antarctic ice sheets during the glacial cycles. Quaternary Science Reviews 21(1-3), 203-231. doi: 10.1016/ S0277-3791(01)00082-8

Imbrie J and 8 others (1984) The orbital theory of Pleistocene climate: support from a revised chronology of the marine delta18 O record. In Berger A, Imbrie J, Hays J, Kukla G and Saltzman B (eds), Milankovitch and Climate: Understanding the Response to Astronomical Forcing, volume 1 (NATOASI Series C: Mathematical and Physical Sciences, 126). Dordrecht: D. Reidel Pub. Co., pp. 269-305. (doi: 10013/epic.48655).

Jordan TM and 8 others (2018) A constraint upon the basal water distribution and thermal state of the Greenland Ice Sheet from radar bed echoes. The Cryosphere 12(9), 2831-2854. doi: 10.5194/tc-12-2831-2018

Kobashi T and 7 others (2011) High variability of Greenland surface temperature over the past 4000 years estimated from trapped air in an ice core. Geophysical Research Letters 38(21), L21501. doi: 10.1029/ 2011GL049444

Larour E, Morlighem M, Seroussi H, Schiermeier J and Rignot E (2012) Ice flow sensitivity to geothermal heat flux of Pine Island Glacier, Antarctica. Journal of Geophysical Research: Earth Surface 117(F4), F04023. doi: 10. 1029/2012JF002371

Le Meur E and Huybrechts P (1996) A comparison of different ways of dealing with isostasy: examples from modelling the Antarctic ice sheet during the last glacial cycle. Annals of Glaciology 23, 309-317. doi: 10.3189/ S0260305500013586

Martos YM and 5 others (2018) Geothermal heat flux reveals the Iceland hotspot track underneath greenland. Geophysical Research Letters 45(16), 8214-8222. doi: 10.1029/2018GL078289

Mordret A (2018) Uncovering the Iceland hot spot track beneath greenland. Journal of Geophysical Research: Solid Earth 123(6), 4922-4941. doi: 10. 1029/2017JB015104

Oswald GKA and Gogineni SP (2008) Recovery of subglacial water extent from Greenland radar survey data. Journal of Glaciology 54(184), 94-106. doi: $10.3189 / 002214308784409107$

Oswald GKA and Gogineni SP (2012) Mapping basal melt under the northern Greenland Ice Sheet. IEEE Transactions on Geoscience and Remote Sensing 50(2), 585-592. doi: 10.1109/TGRS.2011.2162072

Oswald GK, Rezvanbehbahani S and Stearns LA (2018) Radar evidence of ponded subglacial water in Greenland. Journal of Glaciology 64(247), 711-729. doi: $10.1017 /$ jog.2018.60

PhippsMorgan J and Holtzman BK (2005) Vug waves: a mechanism for coupled rock deformation and fluid migration. Geochemistry, Geophysics, Geosystems 6(8), Q08002. doi: 10.1029/2004GC000818

Pittard ML, Galton-Fenzi BK, Roberts JL and Watson CS (2016) Organization of ice flow by localized regions of elevated geothermal heat flux. Geophysical Research Letters 43(7), 3342-3350. doi: 10.1002/2016GL068436

Poinar K and 5 others (2015) Limits to future expansion of surface-meltenhanced ice flow into the interior of western Greenland. Geophysical Research Letters 42(6), 1800-1807. doi: 10.1002/2015GL063192

Poinar K and 5 others (2017) Drainage of Southeast Greenland Firn Aquifer Water through crevasses to the bed. Frontiers in Earth Science 5, 5. ISSN 2296-6463. doi: 10.3389/feart.2017.00005

Pollack HN, Hurter SJ and Johnson JR (1993) Heat flow from the Earth's interior: analysis of the global data set. Reviews of Geophysics 31(3), 267-280. doi: 10.1029/93RG01249 
Reeh N (1991) Parameterization of melt rate and surface temperature in the Greenland ice sheet. Polarforschung 59(3), 113-128. doi: 10013/epic.29636

Rezvanbehbahani S, Stearns LA, Kadivar A, Walker JD and van der Veen CJ (2017) Predicting the Geothermal Heat Flux in Greenland: A Machine Learning Approach. Geophysical Research Letters 44(24), 12,271-12,279. doi: 10.1002/2017GL075661

Rezvanbehbahani S, van der Veen CJ and Stearns LA (2019a) Fractal properties of greenland isolines. Mathematical Geosciences, 1-16. doi: https://doi. org/10.1007/s11004-019-09788-7

Rezvanbehbahani S, van der Veen CJ and Stearns LA (2019b) An improved analytical solution for the temperature profile of ice sheets. Journal of Geophysical Research: Earth Surface 124(2), 271-286. doi: 10.1029/ 2018JF004774

Rippin DM (2013) Bed roughness beneath the Greenland ice sheet. Journal of Glaciology 59(216), 724-732. doi: 10.3189/2013JoG12J212

Robin GQ (1955) Ice movement and temperature distribution in glaciers and ice sheets. Journal of Glaciology 2(18), 523-532. doi: 10.3189/ 002214355793702028

Robinson A, Calov R and Ganopolski A (2010) An efficient regional energymoisture balance model for simulation of the Greenland ice sheet response to climate change. The Cryosphere 4(2), 129-144. doi: 10.5194/tc-4-129-2010

Rogozhina I and 6 others (2012) Effects of uncertainties in the geothermal heat flux distribution on the Greenland Ice Sheet: an assessment of existing heat flow models. Journal of Geophysical Research: Earth Surface 117(F2), F02025. doi: 10.1029/2011JF002098

Rogozhina I and 9 others (2016) Melting at the base of the Greenland ice sheet explained by Iceland hotspot history. Nature Geoscience 9(5), 366-369. doi: 10.1038/ngeo2689

Rückamp M, Greve R and Humbert A (2019) Comparative simulations of the evolution of the Greenland ice sheet under simplified Paris Agreement scenarios with the models SICOPOLIS and ISSM. Polar Science 21, 14-25. doi: 10.1016/j.polar.2018.12.003

Schroeder DM, Blankenship DD and Young DA (2013) Evidence for a water system transition beneath Thwaites Glacier, West Antarctica. Proceedings of the National Academy of Sciences 110(30), 12225-12228. doi: 10.1073/pnas. 1302828110

Sclater JG, Jaupart C and Galson D (1980) The heat flow through oceanic and continental crust and the heat loss of the Earth. Reviews of Geophysics 18(1), 269-311. doi: 10.1029/RG018i001p00269

Seroussi H and 5 others (2013) Dependence of century-scale projections of the Greenland Ice Sheet on its thermal regime. Journal of Glaciology 59(218), 1024-1034. doi: 10.3189/2013JoG13J054

Shapiro NM and Ritzwoller MH (2004) Inferring surface heat flux distributions guided by a global seismic model: particular application to Antarctica. Earth and Planetary Science Letters 223(1), 213-224. doi: 10.1016/j.epsl. 2004.04.011

Sommers A, Rajaram H and Morlighem M (2018) SHAKTI: subglacial hydrology and kinetic, transient interactions v1. 0. Geoscientific Model Development 11(7), 2955-2974. doi: 10.5194/gmd-11-2955-2018

Stevens NT, Parizek BR and Alley RB (2016) Enhancement of volcanism and geothermal heat flux by ice-age cycling: a stress modeling study of Greenland. Journal of Geophysical Research: Earth Surface 121(8), 1456-1471. doi: 10.1002/2016JF003855

Van den Broeke M and 8 others (2009) Partitioning recent Greenland mass loss. Science 326(5955), 984-986. doi: 10.1126/science.1178176

Van der Veen CJ, Leftwich T, Von Frese R, Csatho BM and Li J (2007) Subglacial topography and geothermal heat flux: potential interactions with drainage of the Greenland ice sheet. Geophysical Research Letters 34(12), L12501. doi: 10.1029/2007GL030046

Van Liefferinge B and 6 others (2018) Promising oldest ice sites in East Antarctica based on thermodynamical modelling. The Cryosphere 12(8), 2773-2787. doi: 10.5194/tc-12-2773-2018

Van Liefferinge B and Pattyn F (2013) Using ice-flow models to evaluate potential sites of million year-old ice in Antarctica. Climate of the Past 9(5), 2335-2345. doi: 10.5194/cp-9-2335-2013

Zhu $\mathbf{H}$ and 5 others (2016) Inversion of geothermal heat flux in a thermomechanically coupled nonlinear Stokes ice sheet model. The Cryosphere 10(4), 1477-1494. doi: 10.5194/tc-10-1477-2016 